\title{
Resource assessment and optimization study of efficient type hybrid power system for electrification of Rural District in Ethiopia
}

\author{
Samuel Tesema ${ }^{1, *}$, Getachew Bekele ${ }^{2}$ \\ ${ }^{1}$ Department of Electrical and Computer Engineering, Arba Minch University, Arba Minch, Ethiopia \\ ${ }^{2}$ School of Electrical Engineering, Addis Ababa University, Addis Ababa, Ethiopia \\ Email address: \\ samuel.tesema@amu.edu.et(S. Tesema),getachewbk@gmail.com (G. Bekele)
}

\section{To cite this article:}

Samuel Tesema, GetachewBekele. Resource Assessment and Optimization Study of Efficient Type Hybrid Power System for Electrification of Rural District in Ethiopia. International Journal of Energy and Power Engineering. Vol. 3, No. 6, 2014, pp. 331-340.

doi: $10.11648 /$ j.ijepe.20140306.16

\begin{abstract}
The Somali region in Ethiopia enjoys an average wind speed of $5 \mathrm{~m} / \mathrm{s}$ at $10 \mathrm{~m}$ elevation and an average daily solar radiation of $7.5 \mathrm{kwh} / \mathrm{m}^{2} /$ day. Within this perspective, a remote rural village in Somali region calledWerder district $(6050$ ' $\mathrm{N}$ $45030^{\prime}$ E) can be electrified with a stand-alone hybrid renewable energy system. The village is far away from the national electric grid and the electrical load density in the village is low. Extension of national grid to this village which is located $576 \mathrm{~km}$ away from national grid is not economically feasible. Therefore, this study aims to explore techno-economic analysis of electrifying the village with hybrid renewable energy. The software HOMER was used in this study to evaluate the technical and economic feasibility of various hybrid energy alternatives to the village. The economic analysis compares the levelized cost of electricity generation for the three option; wind/PV/diesel generator, diesel generator only system and national grid extension. The levelized cost focusing on the elements causing differences such as fuel price, PV modules, with battery or generator rather than the elements that are similar across the technology choices (distribution, metering, etc). The finding indicate that photovoltaic/wind/diesel generator hybrid system was feasible systems based on some important parameters such as high renewable penetration, less annual diesel consumption, less carbon dioxide emission, less unmet load, less capacity shortage and cost of energy. A thermal load (boiler) is added to the system that uses the excess power generation during the night rather than dissipating it to the dump load; which greatly improved the efficiency of the system at small cost of diesel to the boiler.
\end{abstract}

Keywords: Hybrid System, Homer, Grid Extension, Wind, Solar, Optimization

\section{Introduction}

The rural communities in Ethiopia have low access to energy, both for subsistence and productive purposes, and rely almost entirely on biomass fuels. The consumption of wood fuel has far exceeded its supply. The growing concern of global warming, depletion of petroleum reserves and the continuous increment of oil price have all led to the searching of alternative energy from renewable resources. Energy production from solar and wind resources is becoming a trend both in developed and developing countries. Since Ethiopia is located at the equator, there is a huge potential of solar radiation and considerable potential of wind speed in some part of the country for electrical power production. Like several other developing countries, Ethiopia is characterized by severe energy deficit. In most of the remote and non-electrified sites, extension of utility grid lines experiences a number of problems such as high capital investment, high lead time, low load factor, poor voltage regulation and frequent power supply interruptions. Therefore decentralized energy supply system is the best option for rural electrification in light of technical and economic considerations. Out of around 90 million people in Ethiopia, more than $85 \%$ lives in rural areas and difficult to electrify them by using the national grid either due to economic as well as geographic constraints. The cost to install and service the distribution lines is considerably higher for remote areas. Also there will be a substantial increase in transmission line losses in addition to poor power supply reliability in rural grid. In 2007 , average electricity 
generation mix of the country was composed of $86 \%$ hydro, $13 \%$ Diesel and 1\% geothermal [1]. Since hydro component is highly variable depending on the weather conditions, the increasing demand has to be met through imported dieselbased generation. The energy consumption in Ethiopia from national grid was 3894.0GWh during the 2009/2010 fiscal year [2]. Annual per capita consumption of electricity is 100
$\mathrm{kWh}$ which is much lower than the Sub-Saharan Africa average $510 \mathrm{kWh}$. Due to Economic growth in recent years, the Electricity consumption in the country has been increased and it is common to see small diesel generators running here and there to bridge the electrification gap in rural and preurban areas.

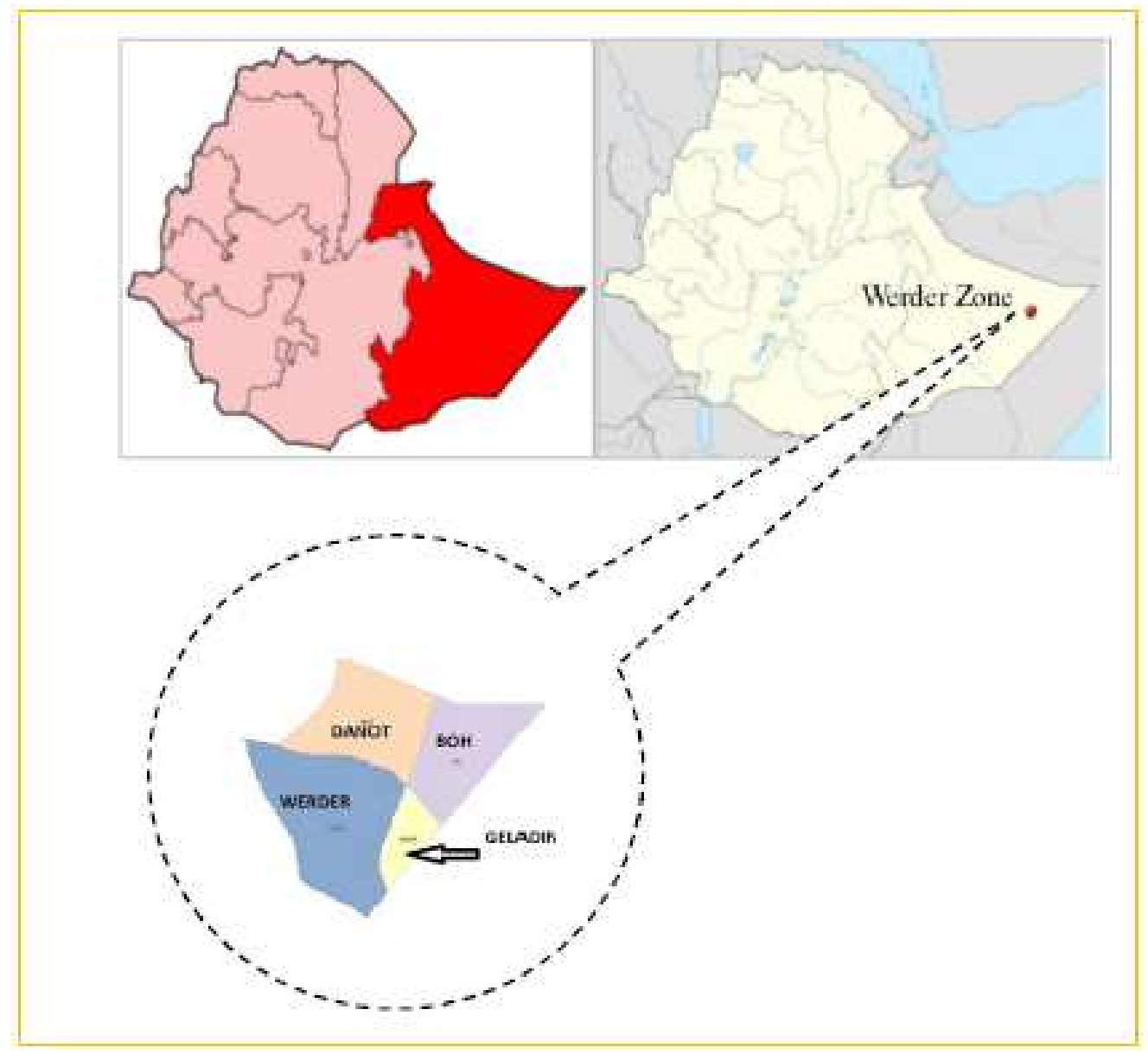

Fig. 1. The study site.

The purpose of this paperis to assess the solar and wind resource potential of the Werder district in Somali region in Ethiopia and to simulate and analyze the techno economic feasibility of hybrid renewable power system to electrify the village in $24 / 7$ bases. Another objective is to compare proposed hybrid system with grid extension and standalone diesel generator in terms of technical and economic feasibility. Hybrid stand-alone electricity generation systems are often considered more reliable and less costly than standalonesystems [3]. In various research papers [4,5], hybrid renewable power systems in off-grid applications have been shown to be economically viable, especially in remote locations. During recent years, the combined use of renewable energy sources, especially wind and solar, is becoming increasingly attractive and being widely used as an alternative to fossil-fuel energy [6]. The study area was electrified with diesel generator which runs three to four hours during night time due to soaring fuel cost. The area is located at $576 \mathrm{~km}$ away from the national grid and has difficulty in transporting fuel due to poor infrastructure (road).

GetachewBekele, 2009 [7] investigated the way of supplying electric energy from solar and wind hybrid resources to remotely located communities detached from the main grid line in Ethiopia. He used sunshine hour data collected over a period of more than 10 years at four different geographical locations (Addis Ababa, Mekele, Nazret, and Debrezeit).Based on the sunshine duration data, the monthly average daily sunshine amount for each of the places has been computed. The results indicate an abundance of solar energy potential of the sites.

GetnetTadesse, 2011 [8] has done a resource assessment of solar, hydro and wind power potentials available at theDejen district in Ethiopia and proposed optimal hybrid combinations for rural electrification of 10,500 families (with an average of 6 members) using HOMER as optimization and simulation tool. 


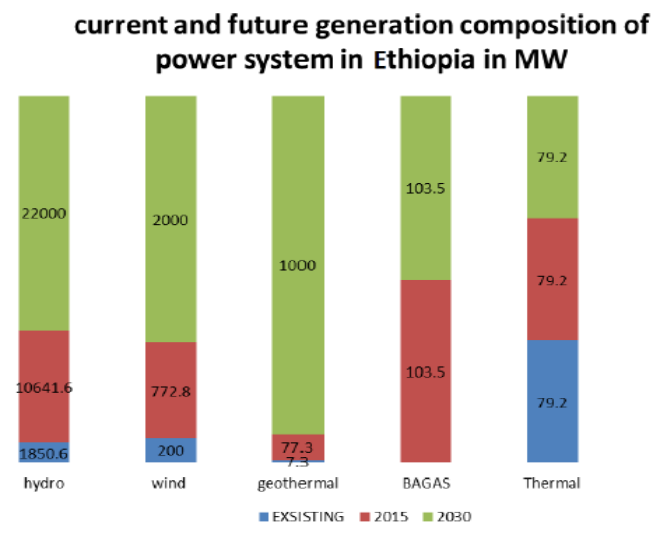

Fig. 2. Current and future energy mix in Ethiopia.

\section{Methodology}

To assess the solar and wind resource of the site relevant data collection has been taken place from three main sources.

a) National Meteorological Service Agency (NMSA), Central Statistical Agency (CSA) and the Ethiopian Electric Power Corporation (EEPCO): Wind speed and direction and sunshine duration data is collected from NMSA whereasinfra-structural and demographic information is taken from CSA. Power transmission system equipment price list, regional grid electrification status and future plan are taken from EEPCO.

b) Site visits and Interview: to assess electric demand of the community and existing electrical load, site visit and informal interview of local people has been done both in person and by phone.

c) Internet (web sites): satellite based wind speed and solar radiation data has been taken from NASA and SWERA database websites. Also thorough market survey and technology options are made for PV modules, wind turbines, diesel generators, converters and storage batteries by consulting several websites.

There are no measured solar radiation data for the region and district in the national meteorological service Agency in Ethiopia. The only data available in theagency are sunshine hour duration data of the district from a nearby meteorological station (KibreDehar) which is converted into radiation data in $\mathrm{kWh} / \mathrm{m}^{2}$ by using analytical method with Angstrom correlation equation [9]. The monthly wind speed data on the site are obtained from NMSA.

\subsection{Solar Resource Assessment of the Site}

Since Ethiopia is located near the equator, its solar resource is obviously of significant potential. The annual average daily radiation in Ethiopia reaching the ground is estimated to be $5.5 \mathrm{kWh} / \mathrm{m}^{2} /$ day which varies from a minimum of $4.5 \mathrm{kWh} / \mathrm{m}^{2} /$ day in July to a maximum value of $6.5 \mathrm{kWh} / \mathrm{m}^{2} /$ day in February and March. The solar radiation potential for different regions throughout the country has been indicated in Figure 3 which ranges between 5.3 and $7.5 \mathrm{kWh} / \mathrm{m} 2$. This study also confirms the study by SWERA for the solar radiation potential of the Somali region which is the highest potential value of $7.5 \mathrm{kWh} / \mathrm{m}^{2}$ in Ethiopia for Werder Zone [10]

The best way of knowing the amount of global solar radiation is to install pyranometers or photovoltaic sensors at as many locations as possible in a given region and follow their day-to-day recording. In case of Ethiopia, since only sunshine duration is measured by NMSA, analytical method of estimating solar radiation from sunshine duration measurement has been used in this paper.

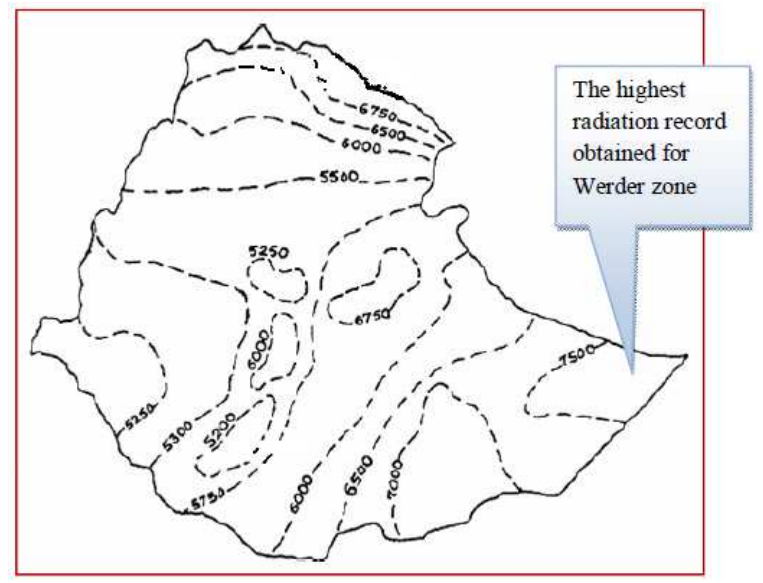

Fig. 3. Solar radiation potential of Ethiopia $\mathrm{Wh} / \mathrm{m} 2$.

\subsubsection{Determination of Solar Radiation by Analytical Method}

There are different methods to get the solar radiation data of a given site. One possibility is to use NASA satellite data which are of course rough estimation of the site. As mentioned, the best way of knowing the amount of global solar radiation for a given site is to install pyranometers or photovoltaic sensors at different location of the region and look after their day-to-day maintenance and recording at least for one year. In our case, only sun hour duration is measurement has been done and correlation equations have been used to get the value ofsolar radiation to the site. Among various correlations, the modified version of Angstrom equation who proposed a linear relationship between the ratio of average daily global radiation to the corresponding value on a completely clear day and the ratio of average daily sunshine duration to the maximum possible sunshine duration and its derivations have been widely used $[11,12,13]$. The Angstrom model is the most commonly used model as given by

$$
H=H_{o}\left[a+\frac{S}{S_{O}} b\right]
$$

Where:

$H=$ monthly average daily radiation on horizontal surface $\left(\mathrm{MJ} / \mathrm{m}^{2}\right)$,

$H_{0}=$ is monthly average daily extraterrestrial radiation on a horizontal surface $\left(\mathrm{MJ} / \mathrm{m}^{2}\right)$

$S_{O}=$ the maximum possible daily hours of bright sunshine

$S=$ monthly average daily number of hours of bright 
sunshine

$a$ and $b$ are regression coefficients which can be obtained using the following equations for $\mathrm{M}$ number of data points.

$$
\begin{gathered}
\mathrm{a}=\frac{\sum \frac{\mathrm{H}}{\mathrm{H}_{\mathrm{O}}} \sum\left(\frac{\mathrm{S}}{\mathrm{S}_{\mathrm{O}}}\right)^{2}-\sum \frac{\mathrm{S}}{\mathrm{S}_{\mathrm{O}}} \sum \frac{\mathrm{S}}{\mathrm{S}_{\mathrm{O}}} \frac{\mathrm{H}}{\mathrm{H}_{\mathrm{O}}}}{\mathrm{M} \sum\left(\frac{\mathrm{S}}{\mathrm{S}_{0}}\right)^{2}-\left(\sum \frac{\mathrm{S}}{\mathrm{S}_{\mathrm{O}}}\right)^{2}} \\
\mathrm{~b}=\frac{\mathrm{M} \sum \frac{\mathrm{S}}{\mathrm{S}_{0}} \frac{\mathrm{H}}{\mathrm{H}_{\mathrm{O}}}-\sum \frac{\mathrm{S}}{\mathrm{S}_{\mathrm{O}}} \sum \frac{\mathrm{H}}{\mathrm{H}_{\mathrm{O}}}}{\mathrm{M} \sum\left(\frac{\mathrm{S}}{\mathrm{S}_{\mathrm{O}}}\right)^{2}-\left(\sum \frac{\mathrm{S}}{\mathrm{S}_{\mathrm{O}}}\right)^{2}}
\end{gathered}
$$

The values of the monthly average daily extraterrestrial radiation $(\mathrm{Ho})$ are calculated for days giving average of each month as
$H_{o}=\left(\frac{24 * 3600}{\pi}\right) G_{s c}\left[\begin{array}{c}\left(1+0.033 \cos \cos \left(\frac{360 n_{d}}{365}\right)\right) * \\ \left(\cos \cos \varnothing \cos \cos \delta \sin \sin \omega_{s}+\frac{2 \pi}{360} \omega_{s} \sin \sin \varnothing \sin \sin \delta\right)\end{array}\right]$

Where:

$n d=$ day number starting from January 1 st as 1 ,

$G_{S C}($ the solar constant $)=1367 \mathrm{~W} / \mathrm{m}^{2}$,

$\phi=$ Latitude of the location,

$\delta=$ Declination angle $\left({ }^{0}\right)$

$\omega_{s}=$ Sunset hour angle $\left({ }^{0}\right)$

The declination angle and sun set hour can be calculated by using the following formulas

$$
\delta=23.45 \sin \sin \left(360 \frac{284+n_{d}}{365}\right)
$$

Where;

\begin{tabular}{|c|c|c|c|c|c|c|c|c|c|}
\hline $\begin{array}{l}\text { Mid of } \\
\text { Month }\end{array}$ & $\mathbf{n}_{\mathbf{d}}$ & $\delta\left({ }^{0}\right)$ & $\omega_{s}$ & $\mathbf{N}$ & $\mathbf{n}$ & Ho $\left(\mathrm{kwh} / \mathrm{m}^{2} / \mathrm{d}\right)$ & $\begin{array}{l}\text { NMSA (Estimat.) } \\
\mathrm{H}\left(\mathrm{kwh} / \mathrm{m}^{2} / \mathrm{d}\right.\end{array}$ & $\begin{array}{l}\text { NASA } \\
\mathrm{Kwh} / \mathrm{m}^{2} / \mathrm{d}\end{array}$ & $\begin{array}{l}\text { SWERANREL } \\
\mathrm{Kwh} / \mathrm{m}^{2} / \mathrm{d}\end{array}$ \\
\hline Jan-15 & 15 & -21.270 & 87.326 & 11.644 & 9.78 & 9.25 & 6.40 & 6.27 & 6.335 \\
\hline Feb-14 & 45 & -13.620 & 88.336 & 11.778 & 9.85 & 9.85 & 6.79 & 6.86 & 6.885 \\
\hline Apr-15 & 105 & 9.415 & 91.138 & 12.152 & 8.91 & 10.47 & 6.76 & 6.01 & 6.491 \\
\hline May-15 & 135 & 18.792 & 92.337 & 12.312 & 7.23 & 10.22 & 5.95 & 5.78 & 6.089 \\
\hline Jun-15 & 166 & 23.314 & 92.960 & 12.395 & 6.83 & 9.98 & 5.66 & 5.35 & 5.867 \\
\hline Jul-15 & 196 & 21.517 & 92.708 & 12.361 & 5.87 & 10.04 & 5.36 & 5.26 & 5.392 \\
\hline Aug-15 & 227 & 13.784 & 91.685 & 12.225 & 6.79 & 10.29 & 5.85 & 5.91 & 6.122 \\
\hline Sep-15 & 258 & 2.217 & 90.266 & 12.035 & 8.35 & 10.34 & 6.50 & 6.29 & 6.68 \\
\hline Oct-15 & 288 & -9.599 & 88.839 & 11.845 & 7.83 & 9.98 & 6.13 & 5.39 & 6.108 \\
\hline Nov-15 & 319 & -19.148 & 87.616 & 11.682 & 8.57 & 9.38 & 6.05 & 5.69 & 6.258 \\
\hline Dec- 15 & 349 & -23.335 & 87.037 & 11.605 & 9.56 & 9.04 & 6.18 & 6.01 & 6.138 \\
\hline Average & & & & & & & 6.218 & 5.96 & 6.286 \\
\hline
\end{tabular}

$n_{d}$ is day number of the year starting at January $1^{\text {st }}$ as 1

Table 1. Calculated, NASA and SWERA average monthly solar radiation value of the site.

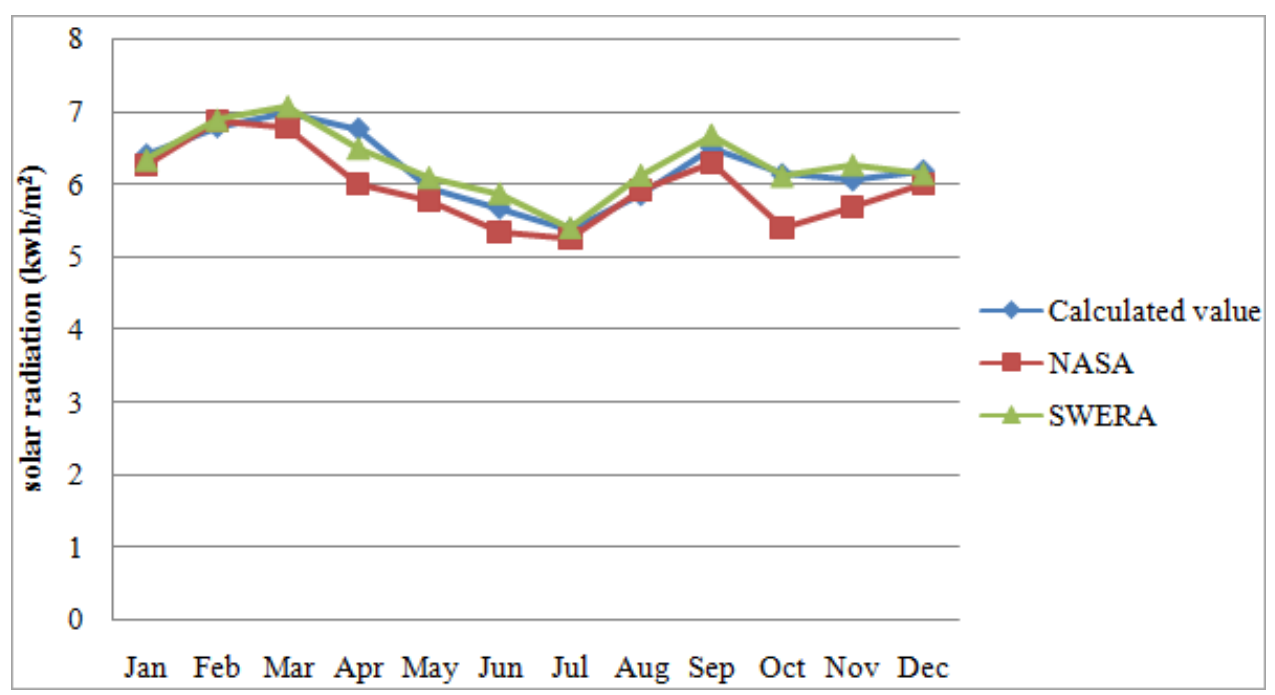

Fig. 4. Comparison of calculated solar radiation data with NASA and SWERA.

\section{Wind Resource Assessment of the Site}

Wind resource is the most important element in projecting turbine performance at a given site. The energy that can be extracted from a wind stream is proportional to the cube of its velocity, meaning that doubling the wind velocity increases the available energy by a factor of eight. Also the wind resource itself varies with year, seasons, time of day, elevation above ground, and form of terrain. The total wind resource of Ethiopia is estimated to be $20.064 \mathrm{TJ} /$ year; however, a significant amount of it had not been harnessed yet throughout the county [17]. As the study [18], there are 
few promising windy areas in Ethiopia located alongside the main East African Rift Valley, the North Eastern escarpment of the country near Tigray regional state, the southern part of Ethiopia near the Kenyan border, the central Ethiopia and eastern part of Ethiopia specially south east of the Somali region.
The wind speed data of the study site have been taken from a nearby metrological station (Kebredehar station) which is measured at 10 meter height. In order to estimate the wind speed at selected turbine hub height $(78 \mathrm{~m})$, the following equation has been used [19].

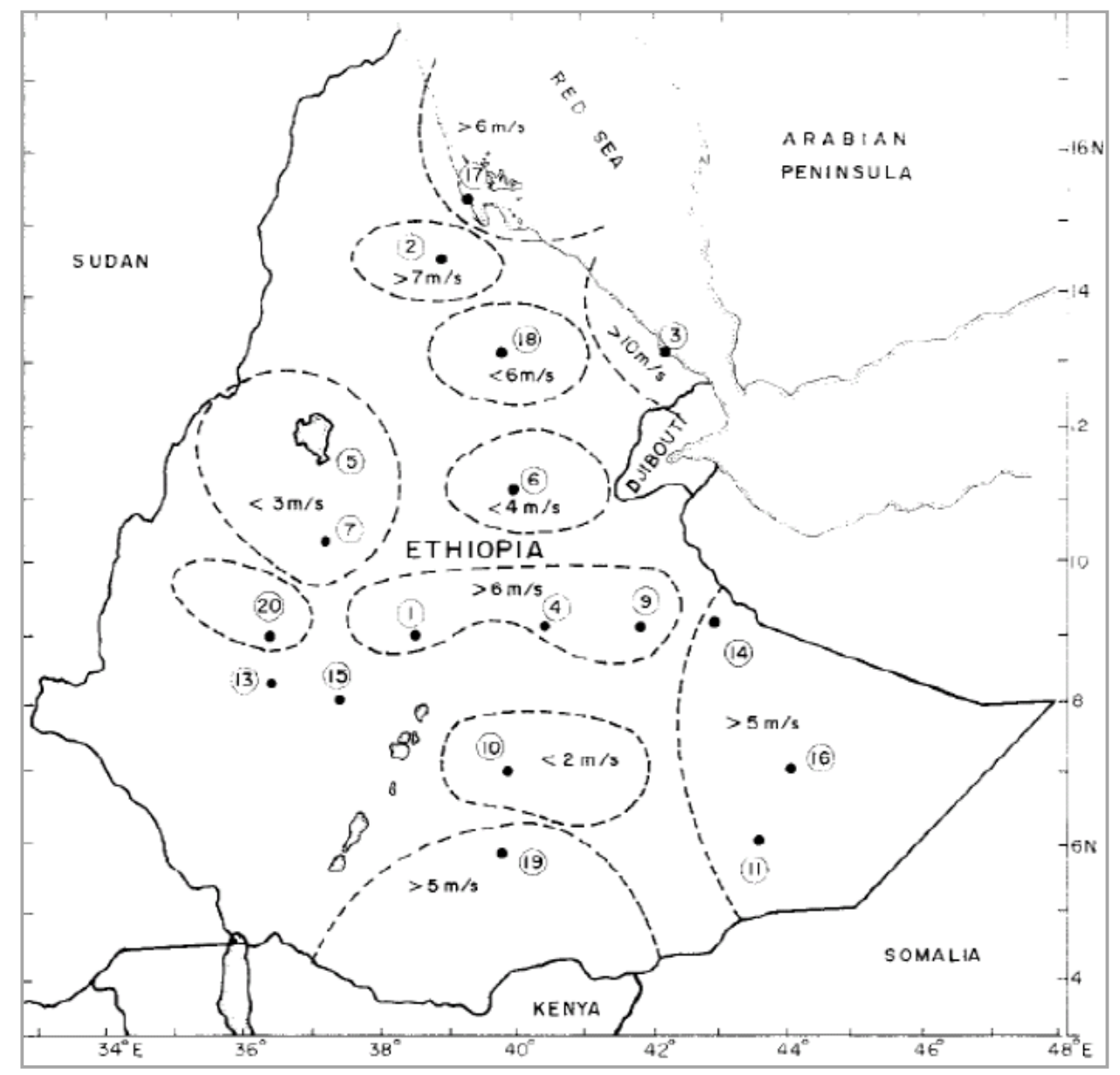

Fig. 5. Solar radiation potential of Ethiopia $\mathrm{Wh} / \mathrm{m}^{2}$.

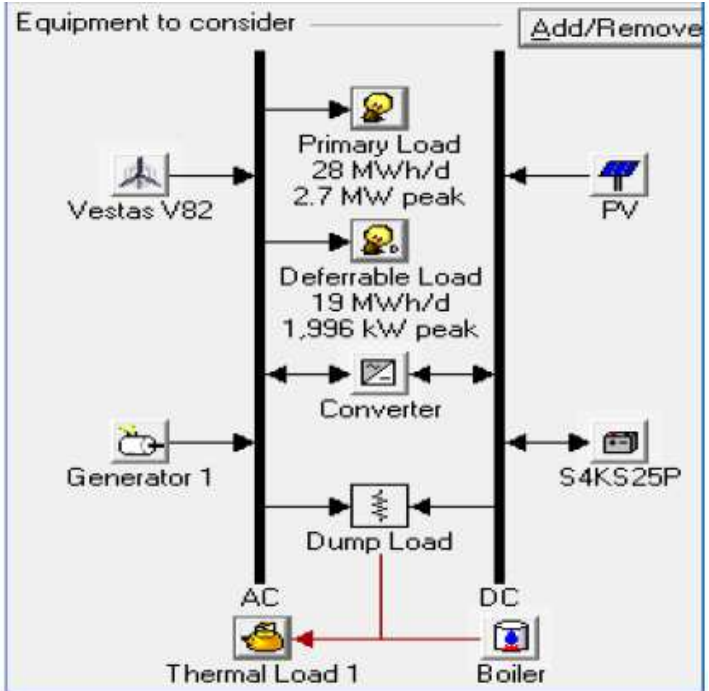

Fig.6. PV/Wind T./Diesel Generator/Battery hybrid power system setup for Werder district.

$$
V(Z) \times \ln \frac{\left(Z_{r}\right)}{Z_{o}}=V\left(Z_{r}\right) \times \ln \left(\frac{Z}{Z_{o}}\right)
$$

Where $z_{r}$ is the reference height $(10 \mathrm{~m}), \mathrm{z}$ is the new hub height, $\mathrm{z}_{\mathrm{o}}$ is the roughness length, which is $0.1-0.25 \mathrm{~m}$ for cropland and a value of 0.15 has been used in the calculation since the site is located in a semi desert area. $\mathrm{V}(\mathrm{z})$ and $\mathrm{V}\left(\mathrm{z}_{\mathrm{r}}\right)$ is the velocity at height $\mathrm{z}$ and $\mathrm{z}_{\mathrm{r}}$ respectively.

\section{Electrical Load Estimation of the Site}

Electrical load assessment in design of Hybrid Renewable Power System is the basic first step to determine the size of system components. It is obvious that community electrical load is firmly related to the life style of the people which in turn is variably expressed by their socioeconomic, religious, cultural, geographical, demographic and technological situations they live in. Just for the purpose of minimizing the complexity in estimating the electrical load of the community 
in the district, 500 households with an average family size of six is assumed in this study. The electrical loads included in the design are: energy efficient type compact fluorescent lamps (CFL), Television, FM/AM radio receiver, water pumps, flour mills, some medical equipment for human and veterinary centers and energy efficient hot plates (stoves). Generally electrical loads are classified into primary and deferrable loads. Primary load is electrical load that must be met immediately in order to avoid unmet load whereas deferrable load is electrical load that must be met within some time period, but the exact timing is not important. Loads are normally classified as deferrable because they have some storage associated with them for instance electrical water pumps. The number and time of usage of the appliance in each household are determined through direct interview and from the experience of electrified village with the same socioeconomic condition. The entire load with corresponding time of usage was put into the Excel spread sheet program and hourly load of the district has been calculated. This is due to the reason that HOMER software needs an hourly load input of a given village.

As shown in the Fig 7 below the district have the energy demand of $28 \mathrm{MWh}$ /day of the primary load with peak load of 2.7 MW and 1.9 MWh of deferrable load with peak load of $1.97 \mathrm{MW}$. Thermal load and boiler are added to the system in order to economically use surplus electricity (increase the efficiency of the system) and to keep the stability of the system.

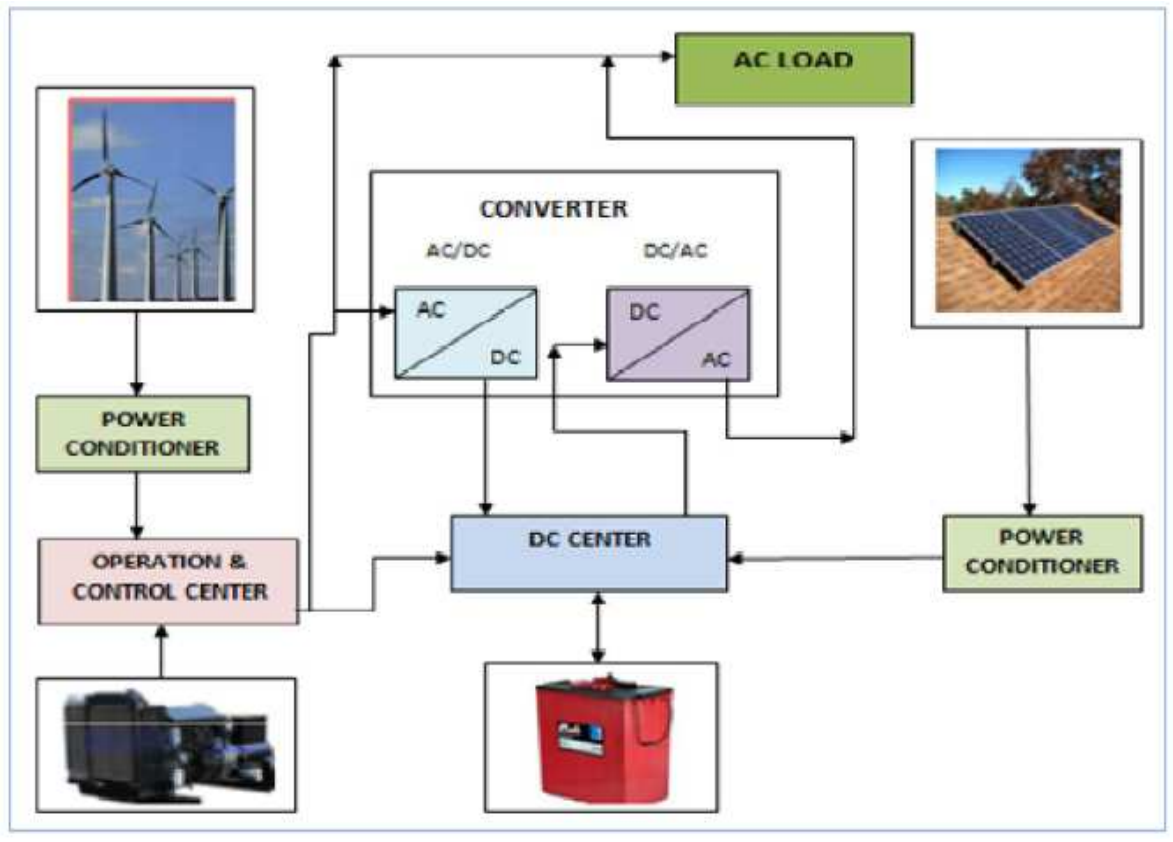

Fig. 7. General schematic diagram of PV/Wind T./Generator/Battery Hybrid power system.

\section{Resource and Component Input}

Homer software needs some resource inputs and component cost and capacity as an optimization parameter in order to select technically and economically feasible combination of hybrid power system. Average solar radiation of the site, average wind speed, hub height of the selected wind turbine is used as resource input. As depict in Fig 6, it needs some technical parameters of selected components such as wind turbine (VESTAS V82), photovoltaic module, diesel generator and battery storage which can be obtained from corresponding manufacturers and through current market survey [20]. The sensitivity variables such as diesel fuel price, load variation, PV capital and replacement cost are used in the optimization process in order to test uncertainty of the aforementioned variables.

Table 2. Component Size and Price Inputs to HOMER software for the site.

\begin{tabular}{|c|c|c|c|c|c|}
\hline & $\begin{array}{l}\text { PV Module (SHARP) } \\
\text { ND-235QCJ }\end{array}$ & $\begin{array}{l}\text { Wind Turbine } \\
\text { VestaV82 }\end{array}$ & $\begin{array}{l}\text { Diesel Generator } \\
\text { Cummins }\end{array}$ & $\begin{array}{l}\text { Battery } \\
\text { Surrette 4KS25PS }\end{array}$ & $\begin{array}{l}\text { Converter } \\
\text { MagnaSineMS- } \\
\text { 4448PAE/240 } \\
\end{array}$ \\
\hline $\operatorname{Size}(\mathrm{KW})$ & 1 & 1,650 & $0-3300$ & $1,900 \mathrm{Ah} / 7.6 \mathrm{KWh}$ & 4.4 \\
\hline Capital (\$) & 2106.4 & $1,262,190$ & $0-613025$ & 1221 & 2608 \\
\hline Replacement cst (\$) & 1755.3 & 757,314 & $0-490420$ & 1163 & 2608 \\
\hline$O \& M \operatorname{cost}(\$ / y)$ & 5 & 2000 & $0-20 / \mathrm{hr}$ & 10 & 40 \\
\hline Quantity & --- & $\begin{array}{l}{[0,5,6,7,8,9,10,} \\
17]\end{array}$ & ---- & $\begin{array}{l}{[0,5,5.5,6,6.5,7.5,9,1} \\
0,16,4,40,60,70]^{\prime} 00\end{array}$ & --- \\
\hline $\begin{array}{l}\text { Sizes to consider } \\
(\mathrm{KW})\end{array}$ & $\begin{array}{l}{[0,6,6.5,8,} \\
8.5,9,9.4,10,25,120,150]^{\prime} 00\end{array}$ & --- & $\begin{array}{l}{[0,9.8,10,11.22,12.5,} \\
13,14.5,15,20,33]^{\prime} 00\end{array}$ & -- & $\begin{array}{l}{[0,7.5,8,8.5,9,9.5,10,} \\
11,19,21,21,26,39]^{\prime} 00\end{array}$ \\
\hline Life Time & 20years & 20years & $25000 \mathrm{hrs}$ & $10569 \mathrm{KWh}$ & Years \\
\hline
\end{tabular}




\section{Result and Discussion}

\subsection{Optimization Result}

The categorized optimization result for Werder district (Table 3) in which all system architecture types are found is listed in the increasing order of total Net Present cost (NPC). There are 11 different feasible system architecture starting from PV/wind T./Generator/Battery to the wind only, solar only and Generator only system architectures in both load following (LF) and cyclic charging (CC) dispatch strategies that meet the electrical load demand and all the pre-set constraints. The costs of energy vary between US $\$ 0.109 / \mathrm{kWh}$ to US $\$ 0.329 / \mathrm{kWh}$ for categorized feasible systems and US $\$ 0.109 / \mathrm{kWh}$ to US $\$ 0.111 / \mathrm{kWh}$ for feasible over all systems. The renewable fractional value, an indication of the available renewable resource, varies from 0 in the diesel generator only case to 0.96 (due to $4 \%$ intake of fuel by the boiler during capacity shortage) in the PV/battery only case, 0.99 in the wind turbine/Battery case in the categorized result group and 0.90 to 0.94 in the overall feasible result group. The capacity shortage was limited at $5 \%$ due to the fact that the system reserve was set at $10 \%$ of the hourly load and $20 \%$ for daily Load; the unmet load fraction varies from 0.017 to 0.048 in the categorized result and 0.03 to 0.033 in the overall result group as shown in the table below.

Table 3. Categorized Optimization Result.

\begin{tabular}{|c|c|c|c|c|c|c|c|c|c|c|c|c|}
\hline Rank & $\begin{array}{l}\text { PV } \\
(\mathbf{k W})\end{array}$ & $\begin{array}{l}\text { W.T } \\
(\mathbf{V 8 2}) \\
\end{array}$ & $\begin{array}{l}\text { D. Gen. } \\
(\mathrm{kW})\end{array}$ & Battery & $\begin{array}{l}\text { Conver. } \\
(\mathrm{KW})\end{array}$ & $\begin{array}{l}\text { Dispatch } \\
\text { Str. }\end{array}$ & $\begin{array}{l}\text { Total NPC } \\
\text { (\$) }\end{array}$ & $\begin{array}{l}\text { COE } \\
(\$ / k W h)\end{array}$ & $\begin{array}{l}\text { Renew. } \\
\text { Frac. }\end{array}$ & $\begin{array}{l}\text { Unmet } \\
\text { Load Fra. }\end{array}$ & $\begin{array}{l}\text { Diesel } \\
(\mathrm{L} / \mathrm{yr})\end{array}$ & $\begin{array}{l}\text { Diesel G. } \\
\text { (hrs/yr) }\end{array}$ \\
\hline 1 & 900 & 8 & 1122 & 650 & 850 & $\mathrm{LF}$ & $23,226,774$ & 0.109 & 0.92 & 0.033 & 639,018 & 3,261 \\
\hline 2 & 0 & 8 & 1300 & 1000 & 850 & $\mathrm{LF}$ & $23,295,852$ & 0.110 & 0.9 & 0.035 & 763,871 & 3,266 \\
\hline 3 & 0 & 8 & 1450 & 0 & 0 & $\mathrm{LF}$ & $24,414,172$ & 0.120 & 0.88 & 0.030 & $1,061,189$ & 4,736 \\
\hline 4 & 850 & 8 & 1250 & 0 & 750 & $\mathrm{LF}$ & $24,705,800$ & 0.120 & 0.9 & 0.028 & 865,507 & 4,553 \\
\hline 5 & 2500 & 8 & 0 & 4000 & 2100 & $\mathrm{CC}$ & $27,524,134$ & 0.130 & 0.98 & 0.035 & 86,451 & 0 \\
\hline 6 & 0 & 17 & 0 & 6000 & 2600 & $\mathrm{CC}$ & $38,121,964$ & 0.190 & 0.99 & 0.041 & 77,040 & 0 \\
\hline 7 & 12000 & 0 & 1500 & 1600 & 3900 & LF & $49,752,076$ & 0.250 & 0.82 & 0.036 & $1,137,317$ & 4,165 \\
\hline 8 & 12000 & 0 & 2000 & 0 & 3900 & $\mathrm{LF}$ & $53,237,868$ & 0.270 & 0.77 & 0.017 & $1,659,291$ & 5,527 \\
\hline 9 & 15000 & 0 & 0 & 7000 & 3900 & $\mathrm{CC}$ & $54,088,892$ & 0.270 & 0.96 & 0.026 & 128,733 & 0 \\
\hline 10 & 0 & 0 & 3300 & 0 & 0 & $\mathrm{LF}$ & $63,117,560$ & 0.329 & 0 & 0.047 & $5,071,921$ & 8,760 \\
\hline 11 & 0 & 0 & 2000 & 2400 & 1900 & $\mathrm{CC}$ & $63,170,576$ & 0.329 & 0 & 0.048 & $4,678,182$ & 8,750 \\
\hline
\end{tabular}

Table 4. Selected over-all system optimization result.

\begin{tabular}{|c|c|c|c|c|c|c|c|c|c|c|c|c|c|c|}
\hline 䒕 & $\sum_{\substack{a \\
2}}^{2}$ & 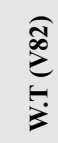 & $\begin{array}{l}\dot{0} \\
\dot{0} \\
\dot{0}\end{array}$ & 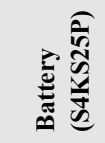 & 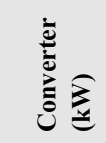 & 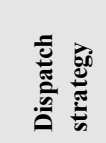 & 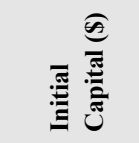 & 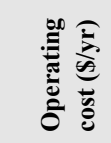 & 岂 & 엉 & 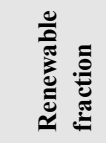 & 冚 & 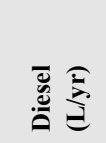 & 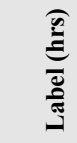 \\
\hline 1 & 900 & 8 & 1122 & 650 & 850 & LF & $13,549,198$ & 830,438 & $23,226,774$ & 0.109 & 0.92 & 0.033 & 639,018 & 3,261 \\
\hline 2 & 900 & 8 & 1122 & 650 & 800 & LF & $13,516,598$ & 833,584 & $23,230,834$ & 0.109 & 0.92 & 0.033 & 643,024 & 3,298 \\
\hline 4 & 850 & 8 & 1122 & 750 & 850 & LF & $13,565,998$ & 829,846 & $23,236,680$ & 0.109 & 0.92 & 0.033 & 634,460 & 3,216 \\
\hline 126 & 850 & 8 & 1122 & 900 & 1050 & LF & $13,879,548$ & 814,528 & $23,371,714$ & 0.11 & 0.93 & 0.032 & 607,472 & 3,040 \\
\hline 157 & 850 & 8 & 1122 & 900 & 1100 & LF & $13,912,148$ & 813,612 & $23,393,636$ & 0.11 & 0.93 & 0.032 & 605,453 & 3,022 \\
\hline 164 & 800 & 8 & 1122 & 1000 & 1050 & LF & $13,896,348$ & 815,367 & $23,398,296$ & 0.11 & 0.93 & 0.032 & 604,239 & 3,004 \\
\hline 189 & 940 & 8 & 1122 & 800 & 1050 & LF & $13,946,988$ & 812,032 & $23,410,070$ & 0.11 & 0.93 & 0.032 & 608,234 & 3,067 \\
\hline 192 & 940 & 8 & 1122 & 750 & 1100 & LF & $13,918,538$ & 814,898 & $23,415,020$ & 0.11 & 0.93 & 0.032 & 612,378 & 3,086 \\
\hline 196 & 800 & 8 & 1122 & 1000 & 1100 & LF & $13,928,948$ & 814,293 & $23,418,384$ & 0.11 & 0.93 & 0.032 & 602,016 & 2,988 \\
\hline 197 & 800 & 9 & 1000 & 700 & 800 & LF & $14,606,575$ & 756,150 & $23,418,436$ & 0.11 & 0.94 & 0.031 & 560,433 & 3,157 \\
\hline 198 & 850 & 9 & 1000 & 600 & 750 & LF & $14,557,175$ & 760,400 & $23,418,560$ & 0.11 & 0.94 & 0.03 & 569,707 & 3,233 \\
\hline
\end{tabular}

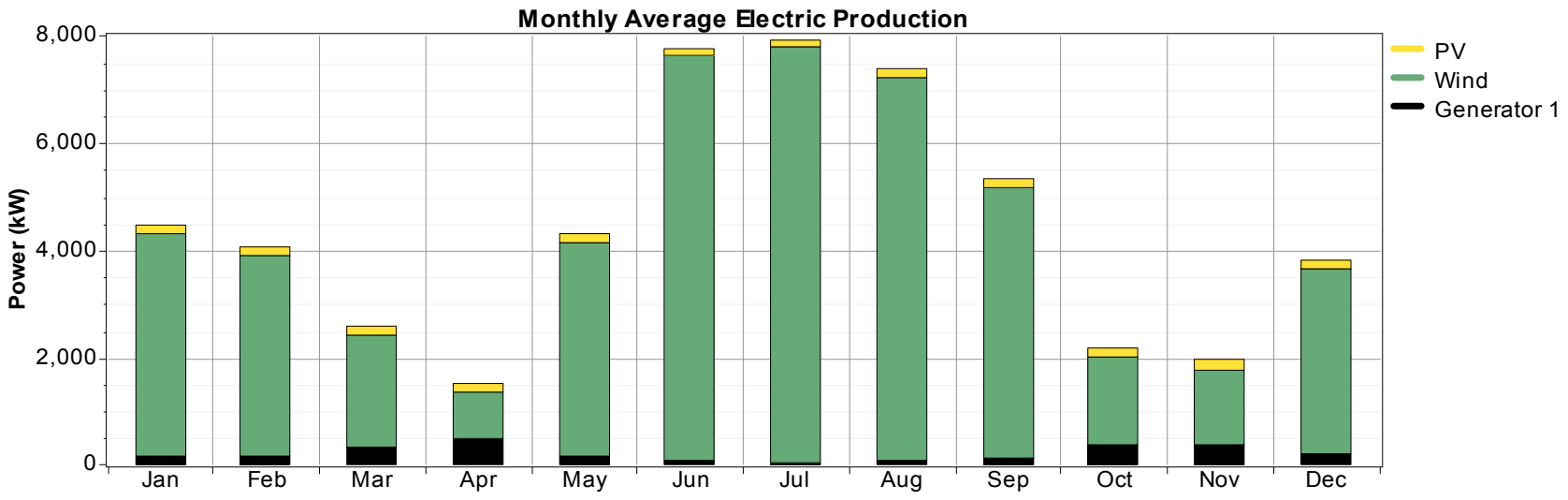

Fig. 8. Average Monthly Electric Production from each source. 


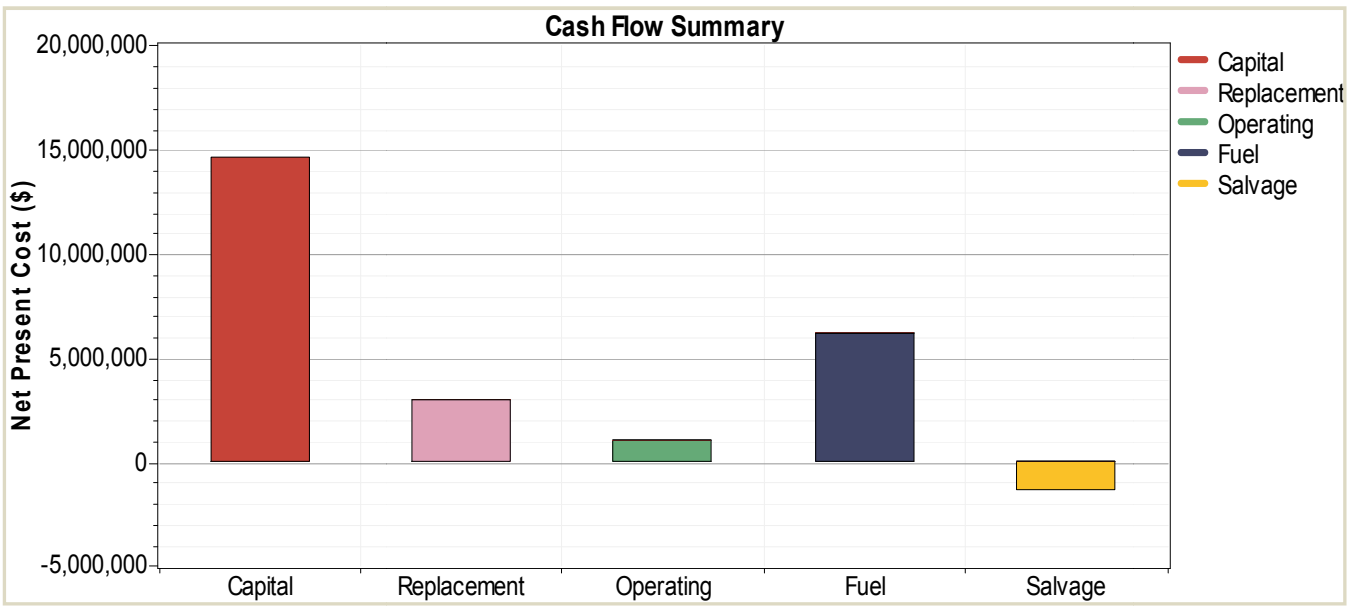

Fig. 9. Life Time Cost In Terms Of Cost Type for Werder District

Table 5. Detail Report on the selected System Architecture.

\begin{tabular}{|c|c|c|}
\hline \multicolumn{3}{|l|}{ System Architecture } \\
\hline \multicolumn{2}{|l|}{$\mathrm{PV}(\mathrm{KW})$} & 800 \\
\hline \multicolumn{2}{|l|}{ Wind T. V82 } & 9 \\
\hline \multicolumn{2}{|l|}{ D. Generators (KW) } & 1000 \\
\hline \multicolumn{2}{|l|}{ Battery (4KS25P) } & 700 \\
\hline \multicolumn{2}{|l|}{ Inverter (KW) } & 800 \\
\hline \multicolumn{2}{|l|}{ Rectifier (KW) } & 800 \\
\hline \multicolumn{2}{|l|}{ Dispatch Strategy } & LF \\
\hline \multicolumn{2}{|c|}{ Electric Production(kWh/yr) } & $\%$ \\
\hline PV array & $1,467,946$ & 4 \\
\hline Wind turbines & $35,643,912$ & 91 \\
\hline Diesel Generator & $1,864,518$ & 5 \\
\hline Total & $38,976,376$ & 100 \\
\hline \multicolumn{2}{|c|}{ Thermal Production(kWh/yr) } & $\%$ \\
\hline Generator & 0 & 0 \\
\hline Excess Electricity & $22,600,842$ & 97 \\
\hline Boiler & 602,977 & 3 \\
\hline Total & $23,203,818$ & 100 \\
\hline Renewable Ratio & 0.94 & \\
\hline \multicolumn{2}{|c|}{ Energy Consumption(kWh/yr) } & $\%$ \\
\hline AC Primary Load & $9,881,386$ & 61 \\
\hline Deferrable Load & $6,211,709$ & 39 \\
\hline Total & $16,093,095$ & 100 \\
\hline Excess electricity & $22,600,842$ & 58 \\
\hline Unmet load & 506,745 & 3.1 \\
\hline Capacity Shortage & 829,508 & 5 \\
\hline Thermal Load & $8,353,971$ & 100 \\
\hline \multicolumn{3}{|l|}{ Cost summary } \\
\hline Total NPC(\$) & \multicolumn{2}{|l|}{$23,418,436$} \\
\hline Levelized COE & \multicolumn{2}{|l|}{$\$ 0.11 / \mathrm{KWh}$} \\
\hline Operating Cost & \multicolumn{2}{|l|}{$\$ 756,150 / \mathrm{yr}$} \\
\hline Pollutant & \multicolumn{2}{|l|}{ Emissions (kg/yr) } \\
\hline Carbon dioxide & \multicolumn{2}{|l|}{$1,476,707$} \\
\hline Carbon monoxide & \multicolumn{2}{|l|}{3,174} \\
\hline Unburned hydrocarbons & \multicolumn{2}{|l|}{352} \\
\hline Particulate matter & \multicolumn{2}{|l|}{239} \\
\hline Sulfur dioxide & \multicolumn{2}{|l|}{2,973} \\
\hline Nitrogen oxides & \multicolumn{2}{|l|}{28,324} \\
\hline
\end{tabular}

\subsection{Sensitivity Analysis}

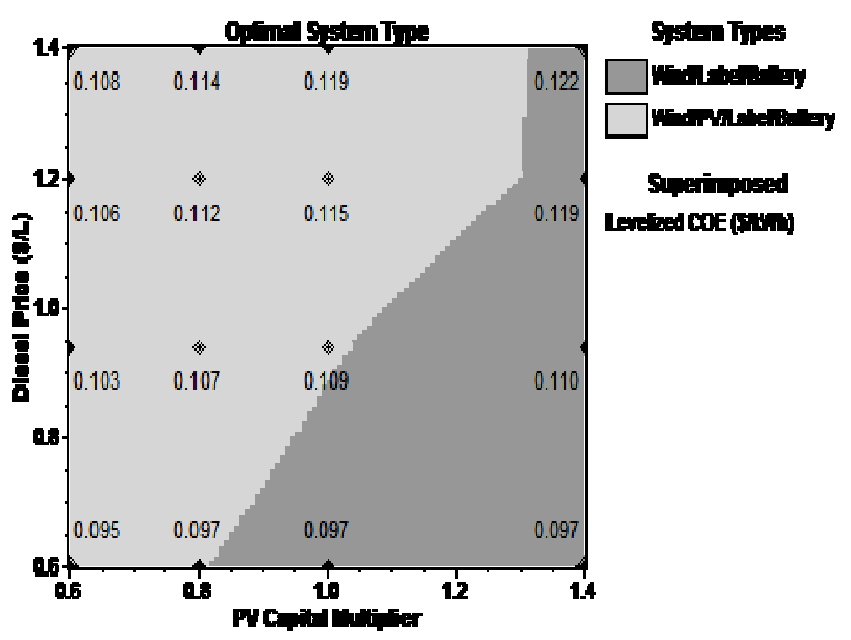

Fig. 10. Result of sensitivity analysis.

The sensitivity analysis was carried out for PV cost and fuel price of diesel generator in order to incorporate possible variations of these variables in the future as shown in the figure below. Wind/PV/diesel Gen/battery system is still cost effective and no longer sensitive to the price of diesel fuel. If the Price of PV module increases by 1.3 times in the future, Wind/Generator/Battery hybrid system will still beeconomically feasible.

\subsection{Hybrid System Comparison with Diesel Generator Only Case}

Optimized result of the diesel generator only power plant serving the same load for all 8760 hours of the year is compared with the hybrid system in terms of lifetime (NPC) cost, Leveleized Cost of Energy (COE), initial capital cost and most importantly with greenhouse gas emission level. The diesel system comparison is an important consideration since it is widely used in Ethiopia for remote area power supply by EEPCo, other cooperatives and nongovernmental organization. The overall lifetime expense of the diesel generator power plant is almost the cost expended for fuel. 
Otherwise, the initial capital cost is almost negligible compared to the other costs and even with the hybrid power system. The COE for the diesel generator only case is US $\$ 0.329 / \mathrm{kWh}$ whereas that of the hybrid system is US $\$ 0.11 / \mathrm{kWh}$. The $\mathrm{CO}_{2}$ emission of the diesel only case is $13,358,930 \mathrm{~kg} / \mathrm{yr}$ where as that of hybrid system is
$1,476,707 \mathrm{~kg} / \mathrm{yr}$ for optimal system as depicted in table 4 at rank 10 . Therefore the hybrid system is economically feasible in terms of life cycle cost and has less $\mathrm{CO}_{2}$ emission which complies with country policy strategy of climate resilient Green Economy [21].

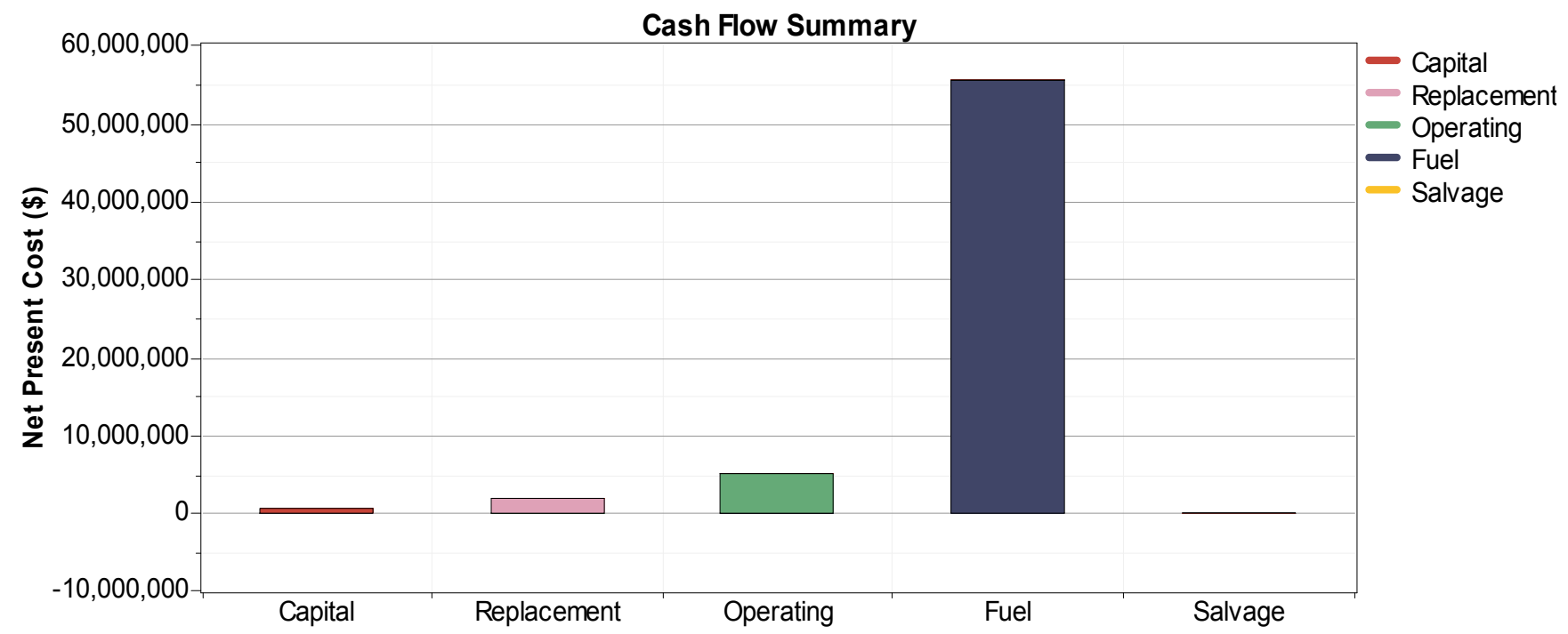

Fig. 11. Cash flow summary of standalone diesel Generator of the site.

\subsection{Hybrid System Comparison with Grid Extension}

As we go further from the national grid, the stand alone hybrid systems (PV/wind/diesel) become more economical. The distance at which the NPC of the standalone system and the grid become equal is known as break even distance and occurred at $65 \mathrm{~km}$ from the grid point above which the hybrid power system more economical as shown in the Fig. 12 sinceWerder district is found at $576 \mathrm{~km}$ from national grid, the hybrid system is the most economical system for this village.

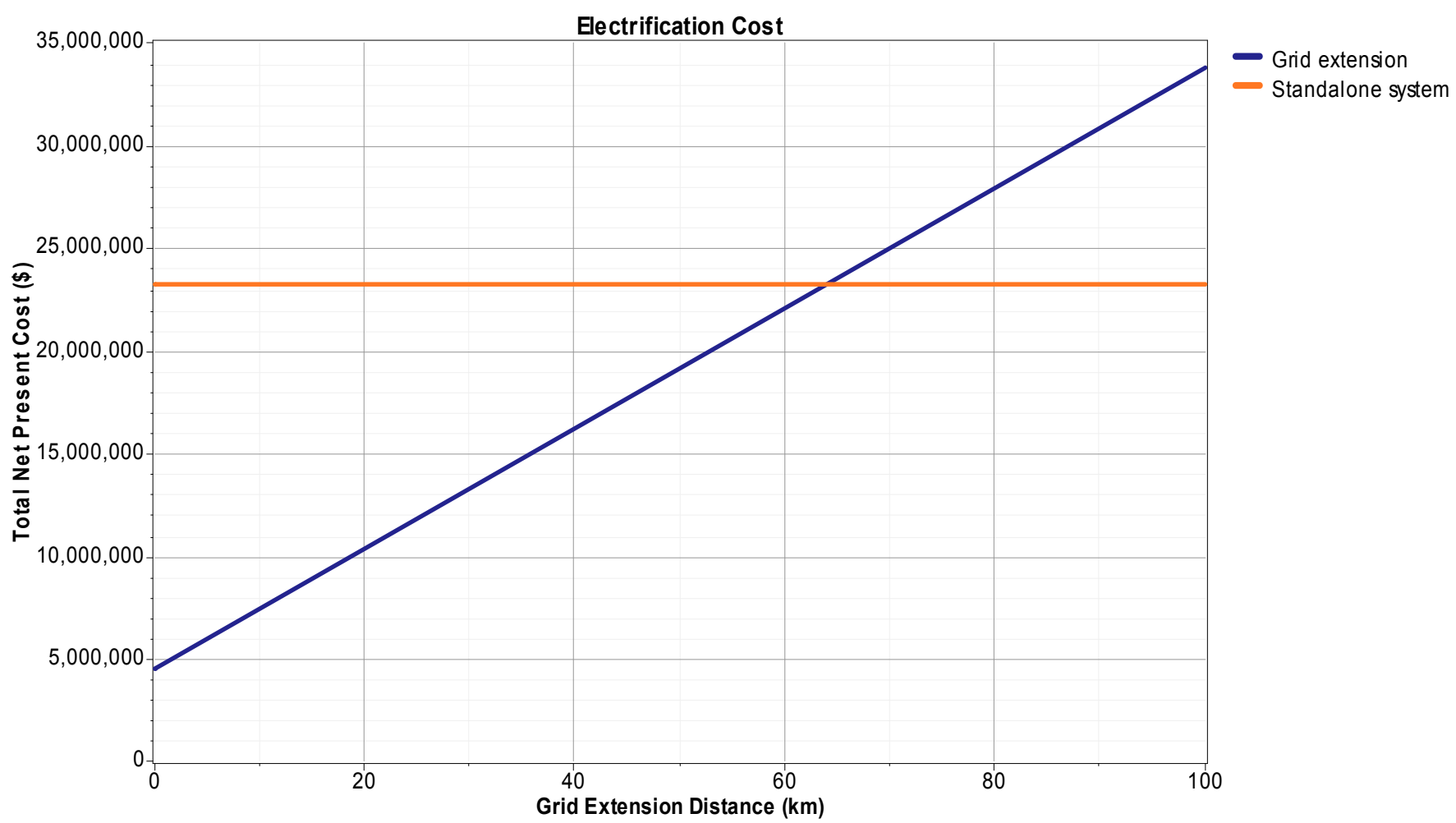

Fig. 12. Break-even Distance of the Hybrid Power System of the proposed site. 
Table 6. Hybrid power system comparison with diesel only and grid extension case.

\begin{tabular}{lllll}
\hline Power System Type & Initial Capital (\$) & Total NPC(\$) & COE(\$/KWh) & Break-even Distance (km) \\
\hline PV/Wind T/Gen/Bat & $14,606,575$ & $23,418,436$ & 0.110 & 64.7 \\
D. Generator & 613,025 & $63,117,560$ & 0.329 & 200 \\
Grid Extension & $106,616,448$ & $275,364,364.8$ & 0.996 & --- \\
\hline
\end{tabular}

\section{Conclusion}

This study aimed at assessing wind and solar resource potential, identifying options and designing of large scale feasible RES to provide electricity for Werder district in Somali region- Ethiopia by harnessing power from renewable energy resources. Three power supply options namely hybrid renewable power system, standalone diesel generator and grid extension options have been considered. Techno economic analysis of this option has been done and hybrid $\mathrm{PV} /$ wind/diesel generator system became economically feasible for the proposed site. HOMER simulation program developed by NREL has been used as optimization and simulation tool and the result was analyzed and the $\mathrm{PV} /$ wind/diesel hybrid system was selected among the many feasible systems based on some important parameters such as high renewable penetration, less annual diesel consumption, less unmet load, less capacity shortage and small levelized cost of energy. Therefore, hybrid renewable power system is the best option among themany possible and feasible systems in the simulation due to its capacity to give electricity nearly the same as grid quality and can electrify the remote site in $24 / 7$ bases with the inclusion of productive use of electricity.The inclusion of thermal load (boiler) to the system made the system very efficient as it uses the excess electricity that the normal loads do not use.

\section{References}

[1] Scaling - Up Renewable Energy Program Ethiopia Investment Plan, ministry of water and Energy

[2] Study on the Energy Sector in Ethiopia Sept 2008 by embassy of Japan

[3] GelmaBoneya, "Design of a photovoltaic-wind hybrid power generation system for Ethiopian remote area", Addis Ababa University, MSc. Thesis, 2011.

[4] Shaahid SM, El-Amin I. "Techno-economic evaluation of offgrid hybrid photovoltaic-diesel-battery power systems for rural electrification in Saudi Arabia - a way forward for sustainable development", Renewable and Sustainable Energy Reviews 2009;13(3):625-33.

[5] Al-Karaghouli A, Kazmerski LL. "Optimization and life-cycle cost of health clinic PV system for a rural area in southern Iraq using HOMER software", Solar Energy 2010;84(4):710-4.

[6] Nema P, Nema RK, Rangnekar S. "A current and future state of art development of hybrid energy system using wind and PV-solar: a review", Renewable and Sustainable Energy Reviews 2009;13(8):2096-103.
[7] B. Getachew, "The Study Into the Potential and Feasibility of Standalone Solar-WindHybrid Electric Energy Supply System for Application in Ethiopia", KTH Royal Institute of Technology Doctoral Thesis, December 2009

[8] T. Getnet, "Feasibility Study of Small Hydro/PV/Wind Hybrid System for Off-GridRural Electrification in Ethiopia," Addis Ababa University MSc. Thesis, 2011.

[9] A. Chukwuemeka , "Solar Radiation in Port Harcourt: Correlation with Sunshine Duration", The Pacific Journal of Science and Technology

[10] AAU, "Renewable Energy Resources Technology: Study of Feasible Options for Rural Electrification in Ethiopia, " Faculty of Technology, Electrical Engineering Department, Final Report Vol. II, Addis Ababa, Ethiopia, 2001

[11] Bakirci, K. 2009. "Correlations for estimation of daily global solar radiation with hours of bright sunshine in Turkey", Energy, 34, 485-501

[12] Ampratwum D.B., Dorvlo A.S.S. 1999. "Estimation of solar radiation from the number of sunshine hours", Applied Energy, $63,161-167$

[13] Chuah D.G.S., Lee S.L., 1981. Solar radiation estimate in Malaysia, Solar Energy, Vol. 26, pp. 33-40.

[14] H.P. Garg and S.N. Garg, "Correlation of Monthly Average Daily Global, Diffuse andBeam Radiation with Bright Sunshine Hours," Energy Conversion Management, vol. 25, p.p. $409-417$

[15] P.K. Veeran and S. Kumar, "Analysis of monthly average daily global radiation and monthly average sunshine duration at two tropical locations," Renewable Energy,vol. 3,p.p. 935-939,

[16] Y. Mulugeta and F. Drake, "Assessment of solar and wind energy resources in Ethiopia:”, Solar Energy, Vol. 57, No. 4, pp. 323-334, 1996

[17] A.V. Ramayya, A. Tirunehe, H. Alemnew, D. Melaku, "Design Performance Simulation and assessment of an $800 \mathrm{~kW}$ wind Turbine for Power Generation at Nazreth," Journal of the Ethiopian Society of Mechanical engineers, vol. 6, No 2, p.p 14-24, 2007.

[18] W. Woldeghiorgis , "Wind Energy Survey in Ethiopia," Journal of Solar \&WindTechnology, Department of Electrical Engineering, Addis Ababa University, AddisAbaba, vol. 5, no. 4, p.p341-351, 1988.

[19] Danish Wind Industry Association (Dec. 2008) http://www.windpower.org/en/tour/wres/index.htm

[20] HOMER, the Optimization Model for Distributed Power: http://www.nrel.gov/homer

[21] The path to sustainable development: Ethiopia's ClimateResilient Green Economy Strategy 